\title{
Relationship Between Cerebral Oxygenation and Phosphorylation Potential During Secondary Energy Failure in Hypoxic-Ischemic Newborn Piglets
}

\author{
TAKASHI KUSAKA, MASAKI UENO, TAKANORI MIKI, TORU KUBOI, SHINJI NAKAMURA, KOSUKE KOYANO, \\ SONOKO IJICHI, SANEYUKI YASUDA, KENSUKE OKUBO, KOU KAWADA, MASANORI NAMBA, TOMOKO NISHIDA, \\ TADASHI IMAI, KENICHI ISOBE, AND SUSUMU ITOH \\ Maternal Perinatal Center [Kusaka, Kuboi, S.Y.]; Departments of Pathology and Host Defense [M.U.]; Departments of Anatomy and \\ Neurobiology [T.M.]; and Departments of Pediatrics [S.N., Koyano, Ijichi, K.O., Kawada, M.N., T.N., T.I., K.I., Itoh], Faculty of \\ Medicine, Kagawa University, Kita-gun, Kagawa 761-0793, Japan
}

\begin{abstract}
The aim of this study was to evaluate the hypothesis that cerebral hemoglobin $(\mathrm{Hb})$ oxygenation is related to phosphorylation potential during primary and secondary cerebral energy failure in newborn infants who have experienced birth asphyxia. We subjected newborn piglets to severe transient cerebral hypoxic-ischemia followed by resuscitation and examined cerebral energy metabolism by ${ }^{31} \mathrm{P}$-magnetic resonance spectroscopy and evaluated changes in cerebral $\mathrm{Hb}$ oxygen saturation $\left(\mathrm{ScO}_{2}\right)$ using full-spectrum nearinfrared spectroscopy before, during, and up to $54 \mathrm{~h}$ after the hypoxic-ischemic insult. $\mathrm{ScO}_{2}$ was significantly decreased during the hypoxic-ischemic insult compared with baseline values. During secondary energy failure, piglets were separated based on the relationship between the ratio of phosphocreatine to inorganic phosphate and $\mathrm{ScO}_{2}$; those with a negative correlation were less injured than those with a positive correlation. These results indicate that changes in $\mathrm{ScO}_{2}$ as measured by near-infrared spectroscopy are related to phosphorylation potential during secondary energy failure in asphyxiated infants. (Pediatr Res 65: 317-322, 2009)
\end{abstract}

$\mathrm{H}$ ypoxic-ischemic encephalopathy remains a major cause of permanent neurodevelopmental disability and infant mortality. Phosphorus nuclear magnetic resonance spectroscopy $\left({ }^{31} \mathrm{P}-\mathrm{MRS}\right)$ has shown that on the first day of life there are no differences in the high-energy phosphate metabolites found in the brains of infants who have experienced birth asphyxia and normal infants $(1,2)$. However, over the next several days, inverse changes in the concentrations of phosphocreatine $(\mathrm{PCr})$ and inorganic phosphate $(\mathrm{Pi})$ cause a significant reduction in the $[\mathrm{PCr}] /[\mathrm{Pi}]$ ratio of asphyxiated infants, despite optimal medical management. Low values of $[\mathrm{PCr}] /[\mathrm{Pi}]$ were found to be associated with very poor prognoses for survival and early neurodevelopmental outcome $(1,2)$. The late metabolic deterioration that is characteristic of asphyxiated infants indicates the existence of metabolic stress

Received May 13, 2008; accepted September 26, 2008.

Correspondence: Takashi Kusaka, M.D., Maternal Perinatal Center, Faculty of Medicine, Kagawa University, Mikicho 1750-1, Kitagun, Kagawa 761-0793, Japan; e-mail: kusaka@kms.ac.jp

This work was supported by Grants-in-Aid for Scientific Research (C) grant 19591281, 15591159, and (B) 17390307, and Encouragement of Young Scientists grant 14770571 and 13770619 from the Ministry of Education, Culture, Sports, Science, and Technology of Japan. and implies that there may be a therapeutic window during which appropriate therapy could improve outcomes.

Near-infrared spectroscopy (NIRS), which uses light in the near-infrared range, can detect changes in the oxygenation state of hemoglobin $(\mathrm{Hb})$ and water in biologic tissues. Several studies have shown the usefulness of NIRS as a noninvasive means of measuring hemodynamic changes in infants (3-10), particularly for quantifying cerebral blood volume (CBV) during small-induced changes in arterial oxygen saturation $(4,7)$, for quantifying cerebral blood flow with rapid changes in oxyHb (or indocyanine green as an intravascular tracer) $(5,8,9)$, and for quantifying cerebrovenous oxygen saturation during downward tilting of the head or jugular venous occlusion (10).

Cerebral vascular $\mathrm{Hb}$ oxygen saturation $\left(\mathrm{ScO}_{2}\right)$ is another parameter that can be measured in absolute terms using NIRS without manipulating inspired oxygen concentration or impeding venous outflow. The output value is the weighted average of arterial, capillary, and venous blood $\mathrm{Hb}$ oxygenation (11-14). $\mathrm{ScO}_{2}$ measurements have been found to have prognostic value for infants with asphyxia or infants who have undergone surgery for congenital transposition of the great vessels (15-17). However, a relationship between $\mathrm{ScO}_{2}$ and cerebral energy state has not been validated in infants with asphyxia.

In this study, we subjected newborn piglets to severe transient cerebral hypoxic-ischemic (HI) insult followed by resuscitation and observed cerebral energy metabolism via ${ }^{31} \mathrm{P}$-MRS and observed changes in $\mathrm{ScO}_{2}$ by full-spectrum NIRS before the insult, during the insult, and up to $54 \mathrm{~h}$ after the insult. We aimed to evaluate the hypothesis that changes in $\mathrm{ScO}_{2}$ are related to changes in phosphorylation potential during secondary cerebral energy failure as assessed by ${ }^{31} \mathrm{P}-\mathrm{MRS}$.

\section{METHODS}

Animal preparation. The study protocol was approved by the Animal Care and Use Committee for Kagawa University. Eight newborn piglets obtained within $24 \mathrm{~h}$ of birth and weighing $1.70-1.90 \mathrm{~kg}$ were used in this study. The

Abbreviations: NIRS, near-infrared spectroscopy; PCr, phosphocreatine; ${ }^{31} \mathbf{P}$-MRS, phosphorus nuclear magnetic resonance spectroscopy; Pi, inorganic phosphate; $\mathbf{S c O}_{2}$, cerebral hemoglobin oxygen saturation 
animal preparation method for the HI model has been reported in detail (18). Briefly, after sedation with an intramuscular injection of sodium pentobarbital $(2 \mathrm{mg} / \mathrm{kg})$, the umbilical artery and vein of each piglet were cannulated. Maintenance solution (electrolytes plus 2.7\% glucose, KN3B; Otsuka Pharmaceutical Co., Tokyo, Japan) was infused continuously at a rate of 4 $\mathrm{mL} / \mathrm{kg} / \mathrm{h}$ via the umbilical vein (thus, glucose was infused at a rate of 2 $\mathrm{mg} / \mathrm{kg} / \mathrm{min}$ ). The piglets were then paralyzed with pancuronium bromide at an initial dose of $0.1 \mathrm{mg} / \mathrm{kg}$ followed by infusion at $0.1 \mathrm{mg} / \mathrm{kg} / \mathrm{h}$, anesthetized with fentanyl citrate at an initial dose of $10 \mu \mathrm{g} / \mathrm{kg}$ followed by infusion at 5 $\mu \mathrm{g} / \mathrm{kg} / \mathrm{h}$, intubated, and mechanically ventilated with an infant ventilator. Each piglet was then placed on a heated-water mattress inside the bore of the magnet. Physiologic variables were monitored and full intensive care was provided throughout the duration of the experiment. Previously, we showed that there were no changes in the phosphorylation potential of the brains of eight piglets over a period of $27 \mathrm{~h}$ under the same conditions of anesthesia as were used in the present study (18). Therefore, we assumed that any secondary energy failure observed in the test animals in this study was caused by HI injury and not by long-term effects of anesthesia. Thus, no control animals were used in this study.

Full-spectrum NIRS. We previously reported the sensitivity and reliability of our full-spectrum NIRS procedure in a phantom model, an animal model, and in a clinical study involving newborn infants immediately after birth $(13,19)$. In our previous study, we used three quartz optical fibers, one for transmission, and the others for detection. In the present study, we used two custom-made long optical fibers for full-spectrum NIRS measurements, one each for transmission and detection. The length of the fibers allowed us to perform NIRS measurements simultaneously with ${ }^{31} \mathrm{P}$-MRS measurements while the piglets were in the magnet. We used a white plate as a reference to convert the spectrum to an absorption spectrum (20).

For NIRS, a photodiode array spectrometer (IMUC-7000; Otsuka Electronics, Osaka, Japan) was used. A stabilized 300-W halogen lamp was used as the light source. Two quartz optical fibers were used, each of which was 1.7 $\mathrm{mm}$ in diameter and $700 \mathrm{~cm}$ in length. One optical fiber was connected to the light source and the other fiber (light-receiving fiber) was coupled to a photodiode array. The sampling time for each scan was $0.5 \mathrm{~s}$.

The relative concentrations of oxyHb and deoxyHb in the brain were calculated using a previously reported method $(13,19)$. Cerebral total $\mathrm{Hb}$ and $\mathrm{ScO}_{2}$ were calculated as follows:

$$
\begin{gathered}
\text { [total } \mathrm{Hb}]=[\text { oxyHb }]+[\text { deoxyHb }], \\
\mathrm{ScO}_{2}(\%)=\{[\text { oxyHb }] /([\text { oxyHb }]+[\text { deoxyHb }])\} \times 100,
\end{gathered}
$$

where [ ] indicates relative concentration.

In this analysis, the absolute value of $\mathrm{Hb}$ could not be calculated but the value of $\mathrm{ScO}_{2}$ could be obtained. We found no significant difference between the value of $\mathrm{ScO}_{2}$ in the piglets using our previous full-spectrum NIRS method $(63.1 \pm 4.0 \%, n=8)$ and that using the method used in this study $(66.9 \pm 6.4 \%, n=8)$ under the condition of normoxia (13).

${ }^{31} \boldsymbol{P}$-MRS. A 2.0 Tesla P-NMR spectroscopy system (Model BEM 250/80, 2.0 Tesla, Otsuka-Electronics, Osaka) was used to measure $[\mathrm{PCr}]$ and $[\mathrm{Pi}]$. A $3-\mathrm{cm}$ diameter surface coil was placed on the top of the skull with the scalp removed to obtain spectra from approximately $7 \mathrm{~mL}$ of brain tissue at a depth of $3 \mathrm{~cm}$ from the surface (21). The mean value of the half-height line-width in the water peak was determined to be $0.4 \mathrm{ppm}$, as established by shimming. A radio frequency pulse of $35.8 \mathrm{MHz}$ was transmitted and received with the same coil at a pulse interval of $2.0 \mathrm{~s}$. The conditions for measurement were a spectral width of $5 \mathrm{kHz}$, spectral data size of 1024 points, a pulse width of 25 $\mu \mathrm{s}$, and sum of 150 samples (total $5 \mathrm{~min}$ ). We recognized that optimal spectral analysis was facilitated by a curve-fitting deconvolution routine. However, because a curve-fitting deconvolution routine was not available and there is a linear correlation between metabolite ratios calculated from peak heights and peak areas (22), the spectra were analyzed by measuring the peak height from the baseline. $[\mathrm{PCr}] /[\mathrm{Pi}]$ was determined from the ratio of $[\mathrm{PCr}]$ and $[\mathrm{Pi}]$ peak heights.

Hypoxic-ischemic insult. After baseline observations, piglets underwent cerebral $\mathrm{HI}$ insult for $55-75 \mathrm{~min}($ mean $=65 \mathrm{~min})$ using a previously reported procedure (18). Cerebral HI insult was induced by inflating a blood pressure cuff positioned around the piglet's neck to $300 \mathrm{~mm} \mathrm{Hg}$ and reducing the inspired oxygen fraction to $0.10-0.06$. Tolazoline hydrochloride $(1-3 \mathrm{mg} / \mathrm{kg})$ was used to prevent a rise in blood pressure during the insult. After the $[\mathrm{PCr}]$ peak had disappeared and $[\beta-\mathrm{ATP}]$ had decreased, the piglets were resuscitated if the [Pi] peak remained constant for 20-25 min. Resuscitation was performed by deflating the blood pressure cuff and providing a fraction of inspired oxygen $\left(\mathrm{FIO}_{2}\right)$ of 0.60 , which was reduced as appropriate to normalize $\mathrm{PaO}_{2}$ after 30 min of resuscitation. Observations were continued for $54 \mathrm{~h}$ after resuscitation. During this period, all piglets received $10-20 \mathrm{~mL}$ of $5 \%$ pig albumin solution and noradrenaline to prevent hypotension. An excess base value of less than $-5.0 \mathrm{mM}$ was corrected as much as possible by sodium bicarbonate infusion. After $54 \mathrm{~h}$, the animals were killed by pentobarbital injection and the brain of each animal was perfused with $0.9 \%$ saline and phosphate-buffered paraformaldehyde.

Histologic evaluation. Histologic evaluations of brain tissue were performed and irregularities were graded according to a neuropathology grading scale for a piglet model of posthypoxic encephalopathy (23). Coronal blocks of the brain were embedded in paraffin, subserially sectioned at $5 \mu \mathrm{m}$, and stained with hematoxylin and eosin. At regular intervals, five sections each of gray matter of the cortex, white matter of the cortex, hippocampus, thalamus, and cerebellum were examined by M.U., who was blinded to the mode of treatment and all clinical information. The extent of damage for each of the five regions was graded in 0.5 intervals on a 9-step scale that ranged from 0.0 to 4.0, as reported by Thoresen et al. (23).

Statistical analysis. The Stat-view 5.0J package for the Macintosh was used for statistical analysis. Values obtained at different times after baseline were compared by Wilcoxon's signed-rank test. Within-subjects regression analysis by Spearman's correlation coefficient by rank test was used to examine the relationships between $[\mathrm{PCr}] /[\mathrm{Pi}]$ and $\mathrm{ScO}_{2}$ and between pathology score and $[\mathrm{PCr}] /[\mathrm{Pi}]$. The extents of brain damage in the different brain regions were compared using paired $t$ test with Bonferroni corrections. The level of statistical significance was set at $p<0.05$ for all tests. All measurement results are expressed as means \pm standard deviation (SD).

\section{RESULTS}

Physiologic parameters. Heart rates, mean arterial blood pressures (MABPs), rectal temperatures, and levels of arterial $\mathrm{pH}(\mathrm{pHa}), \mathrm{PaO}_{2}, \mathrm{PaCO}_{2}$, blood glucose, and lactate in the piglets are shown in Table 1. Zero hour indicates the point at which resuscitation was started after $\mathrm{HI}$ insult. The most significant changes that occurred during the period of acute HI insult were decreases in heart rate, $\mathrm{MABP}, \mathrm{pHa}$, and $\mathrm{PaO}_{2}$, and increases in $\mathrm{PaCO}_{2}$ and lactate, compared with preinsult values.

Table 1. Physiological variables during and after cerebral hypoxia and ischemia $(n=8)$

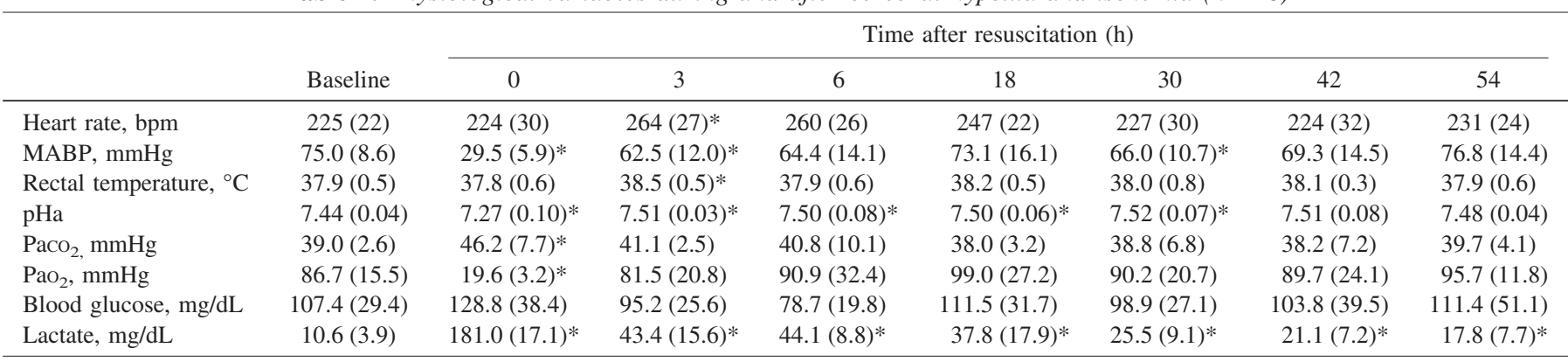

$* p<0.05$ vs. preinsult basal level using Wilcoxon's signed-rank test. Zero hour indicates the point at which resuscitation was started after hypoxic-ischemic insult. Values are means and SDs.

bpm, beats per minute; MABP, mean arterial blood pressure; $\mathrm{pHa}$, arterial $\mathrm{pH} ; \mathrm{PaCO}_{2}$, arterial $\mathrm{PCO}_{2} ; \mathrm{PaO}_{2}$, arterial $\mathrm{Po}_{2}$. 


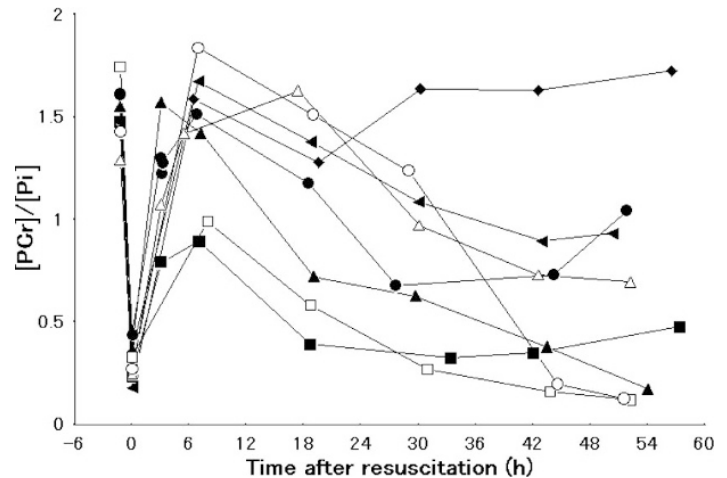

Figure 1. Values of $[\mathrm{PCr}] /[\mathrm{Pi}]$ in the brains of piglets subjected to acute hypoxia-ischemia. Closed symbols $(n=5)$ indicate piglets in which $\mathrm{ScO}_{2}$ showed a negative correlation with $[\mathrm{PCr}] /[\mathrm{Pi}]$ during the period between 6 and $54 \mathrm{~h}$ postresuscitation (group A). Open symbols $(n=3)$ indicate piglets in which $\mathrm{ScO}_{2}$ showed a positive correlation with $[\mathrm{PCr}] /[\mathrm{Pi}]$ (group B).

These values, except for that of lactate, subsequently normalized. pHa increased during the period between 3 and $30 \mathrm{~h}$ postresuscitation.

${ }^{31} \boldsymbol{P}$-MRS. Data for $[\mathrm{PCr}] /[\mathrm{Pi}]$ in the piglets are shown in Figure 1 , and data for $[\mathrm{PCr}] /[\mathrm{Pi}]$ and intracellular $\mathrm{pH}(\mathrm{pHi})$ are summarized in Table 2. [PCr]/[Pi] decreased during the insult from $1.52 \pm 0.14$ to $0.30 \pm 0.09$. This decrease was due to a reduction in $[\mathrm{PCr}]$ combined with a reciprocal and then larger increase in $[\mathrm{Pi}]$. $[\mathrm{PCr}] /[\mathrm{Pi}]$ became greater than one, close to the baseline value, at 3-6 $\mathrm{h}$ after resuscitation and decreased progressively thereafter. At $54 \mathrm{~h}$ postinsult, $[\mathrm{PCr}] /[\mathrm{Pi}]$ had decreased to its minimum value, $0.66 \pm 0.56$, despite that there was no acidosis, hypoxia, or hypotension. During the insult, pHi decreased from $7.13 \pm 0.11$ to $5.73 \pm 0.50$ then returned to the baseline value by $3 \mathrm{~h}$ postresuscitation and did not change until $54 \mathrm{~h}$ postresuscitation.

Cerebral Hb oxygen saturation and total Hb. Data for $\mathrm{ScO}_{2}$ and total $\mathrm{Hb}$ are summarized in Table 2. During the insult, $\mathrm{ScO}_{2}$ decreased from $66.9 \pm 6.4$ to $39.9 \pm 15.6$ and then returned to the baseline value by $3 \mathrm{~h}$ postresuscitation. Figure 2 shows the time course of $\mathrm{ScO}_{2}$ for each piglet. The open symbols indicate piglets for which there was a positive correlation between $\mathrm{ScO}_{2}$ and $[\mathrm{PCr}] /[\mathrm{Pi}]$ during the period between 6 and 54 h postresuscitation. The symbols in Figures 1 and 2 indicate the same piglets. $\mathrm{ScO}_{2}$ was increased at 18 or $30 \mathrm{~h}$ compared with $3 \mathrm{~h}$ postresuscitation, except in one piglet that showed a minimum value of $[\mathrm{PCr}] /[\mathrm{Pi}]$ during secondary energy failure (indicated by an open square in Fig. 2).

Correlations between [PCr] /[Pi] and cerebral $\mathrm{Hb}$ oxygen saturation values during secondary energy failure. The re-

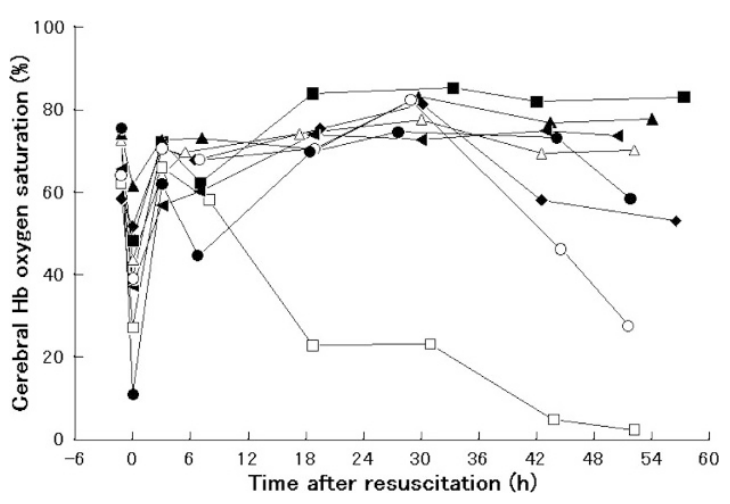

Figure 2. Values of cerebral $\mathrm{Hb}$ oxygen saturation in the brains of piglets subjected to acute hypoxia-ischemia. The symbols indicate the same piglets as shown in Fig. 1.

lationship between $[\mathrm{PCr}] /[\mathrm{Pi}]$ and $\mathrm{ScO}_{2}$ values during the period between 6 and $54 \mathrm{~h}$ postresuscitation was analyzed for each piglet, and the piglets were divided into two groups according to the nature of the relationship: group A $(n=5)$ included piglets with negative correlation coefficients between $[\mathrm{PCr}] /[\mathrm{Pi}]$ and $\mathrm{ScO}_{2}$ values and group $\mathrm{B}(\mathrm{n}=3)$ included that piglets showed positive correlation coefficients between $[\mathrm{PCr}] /$ $[\mathrm{Pi}]$ and $\mathrm{ScO}_{2}$ values (Figs. 3 and 4). In group A, [PCr]/[Pi] and $\mathrm{ScO}_{2}$ values showed a significant negative relationship within subjects $(r=-0.70, p<0.001)$. In group $\mathrm{B},[\mathrm{PCr}] /[\mathrm{Pi}]$ and $\mathrm{ScO}_{2}$ values showed a significant positive relationship within subjects $(r=0.76, p=0.004)$.

Neuropathologic damage. Hematoxylin and eosin staining of gray matter of the cerebral cortex, white matter of the cerebral cortex, hippocampus, and cerebellum representative animals from groups A and B are shown in Fig. 5. Almost all neurons in the gray matter of the cortex in group B showed necrotic morphology, including condensed nuclei and eosinophilic cytoplasm. White matter lesions in group B showed vacuolization of the neuropil and necrotic cells with condensed nuclei. In group B, almost all pyramidal neurons in the CA1 area of the hippocampus showed necrosis, whereas only some of those neurons showed necrosis in group A. Loss and necrosis of Purkinje cells and granular neurons were seen in the cerebellum in group B. Neurons and the neuropil were preserved in extensive areas of gray and white matter of the cerebral cortex and cerebellum in group A. Figure 6 shows the mean pathology scores from the five regions of the brain for groups A and B. Damage in the gray matter of the cortex, subcortical white matter, and thalamus was significantly greater in animals from group B than in animals from group A,

Table 2. $[\mathrm{PCr}] /[\mathrm{Pi}], \mathrm{pHi}$, and cerebral $\mathrm{Hb}$ oxygen saturation during and after cerebral hypoxia and ischemia $(n=8)$

\begin{tabular}{lcccccccc}
\hline & & \multicolumn{5}{c}{ Time after resuscitation $(\mathrm{h})$} \\
\cline { 3 - 7 } & Baseline & 0 & 3 & 6 & 18 & 30 & 42 \\
\hline$[\mathrm{PCr}] /[\mathrm{Pi}]$ & $1.52(0.14)$ & $0.30(0.09)^{*}$ & $1.29(0.32)$ & $1.42(0.33)$ & $1.08(0.46)^{*}$ & $0.85(0.47)^{*}$ & $0.63(0.49)^{*}$ & $0.66(0.56)^{*}$ \\
$\mathrm{pHi}$ & $7.13(0.11)$ & $5.73(0.50)^{*}$ & $7.26(0.10)$ & $7.24(0.15)$ & $7.06(0.10)$ & $7.00(0.13)^{*}$ & $6.94(0.32)$ & $7.01(0.23)$ \\
Cerebral $\mathrm{ScO}_{2}(\%)$ & $66.9(6.4)$ & $39.9(15.6)^{*}$ & $64.9(5.7)$ & $61.7(9.3)$ & $67.7(18.7)$ & $72.6(20.4)$ & $60.7(25.3)$ & $55.8(27.8)$ \\
Cerebral total Hb (a.u.) & $1.000(0)$ & $1.012(0.046)$ & $1.018(0.042)$ & $1.015(0.047)$ & $0.984(0.054)$ & $0.980(0.049)$ & $0.973(0.043)$ & $0.979(0.071)$ \\
\hline
\end{tabular}

Zero hour indicates the point at which resuscitation was started after $\mathrm{HI}$ insult.

Values are means and (standard deviations). ${ }^{*} p<0.05 v s$. preinsult basal level using Wilcoxon's signed-rank test.

$\mathrm{PCr}$, phosphocreatine; $\mathrm{Pi}$, inorganic phosphate; pHi, intracellular $\mathrm{pH} ; \mathrm{ScO}_{2}$, cerebral $\mathrm{Hb}$ oxygen saturation. 


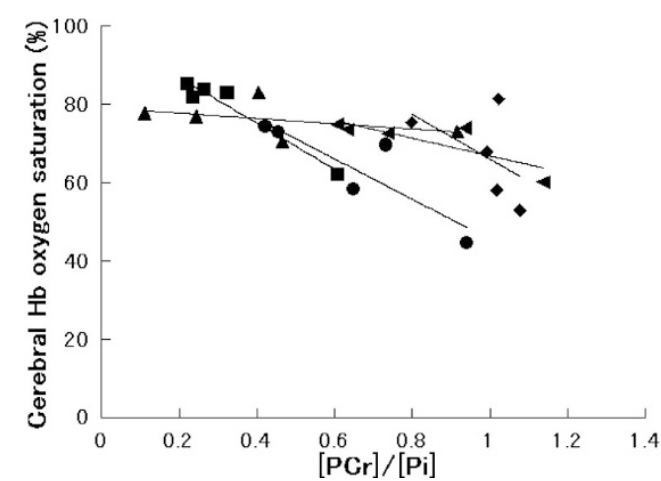

Figure 3. The relationship between $[\mathrm{PCr}] /[\mathrm{Pi}]$ and $\mathrm{ScO}_{2}$ values during the period between 6 and $54 \mathrm{~h}$ after resuscitation for piglets in which $\mathrm{ScO}_{2}$ showed a negative correlation with $[\mathrm{PCr}] /[\mathrm{Pi}]$ (group A, $n=5$ ). $\mathrm{ScO}_{2}$ showed a negative linear correlation with $[\mathrm{PCr}] /[\mathrm{Pi}]$ within subjects $(r=-0.70, p<$ $0.001)$.

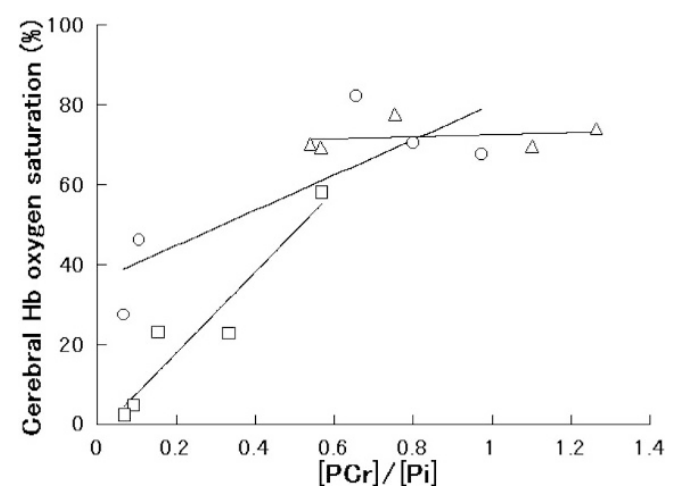

Figure 4. The relationship between $[\mathrm{PCr}] /[\mathrm{Pi}]$ and $\mathrm{ScO}_{2}$ values during the period between 6 and $54 \mathrm{~h}$ after resuscitation in piglets in which $\mathrm{ScO}_{2}$ showed a positive correlation with $[\mathrm{PCr}] /[\mathrm{Pi}]$ (group $\mathrm{B}, n=3$ ). $\mathrm{ScO}_{2}$ showed a positive linear correlation with $[\mathrm{PCr}] /[\mathrm{Pi}]$ within subjects $(r=0.76, p=$ 0.004).

whereas there was no significant difference in damage to the hippocampus and cerebellum between the two groups. In group A, there were significant differences between damage in the hippocampus and damage in the gray matter, white matter, or thalamus, and between damage in subcortical white matter and damage in the cerebellum or thalamus. In group B, there were significant differences between damage in the thalamus and damage in the gray matter or hippocampus and cerebellum. For the eight piglets, the mean pathology score from each of the five sections of the gray matter of the cortex, white matter of the cortex, thalamus, and cerebellum showed a significant negative correlation with the minimum value of $[\mathrm{PCr}] /[\mathrm{Pi}]$ that occurred during the period between 6 and $54 \mathrm{~h}$ postresuscitation.

\section{DISCUSSION}

The results of this study demonstrate a distinct sequence of changes in $\mathrm{ScO}_{2}$ during the early and delayed phases of $\mathrm{HI}$ injury. It is particularly notable that when piglets were separated based on the relationship between $[\mathrm{PCr}] /[\mathrm{Pi}]$ and $\mathrm{ScO}_{2}$ during the period between 6 and $54 \mathrm{~h}$ after resuscitation, those animals with a negative correlation were less injured than those with a positive correlation. The $\mathrm{ScO}_{2}$ measured by NIRS
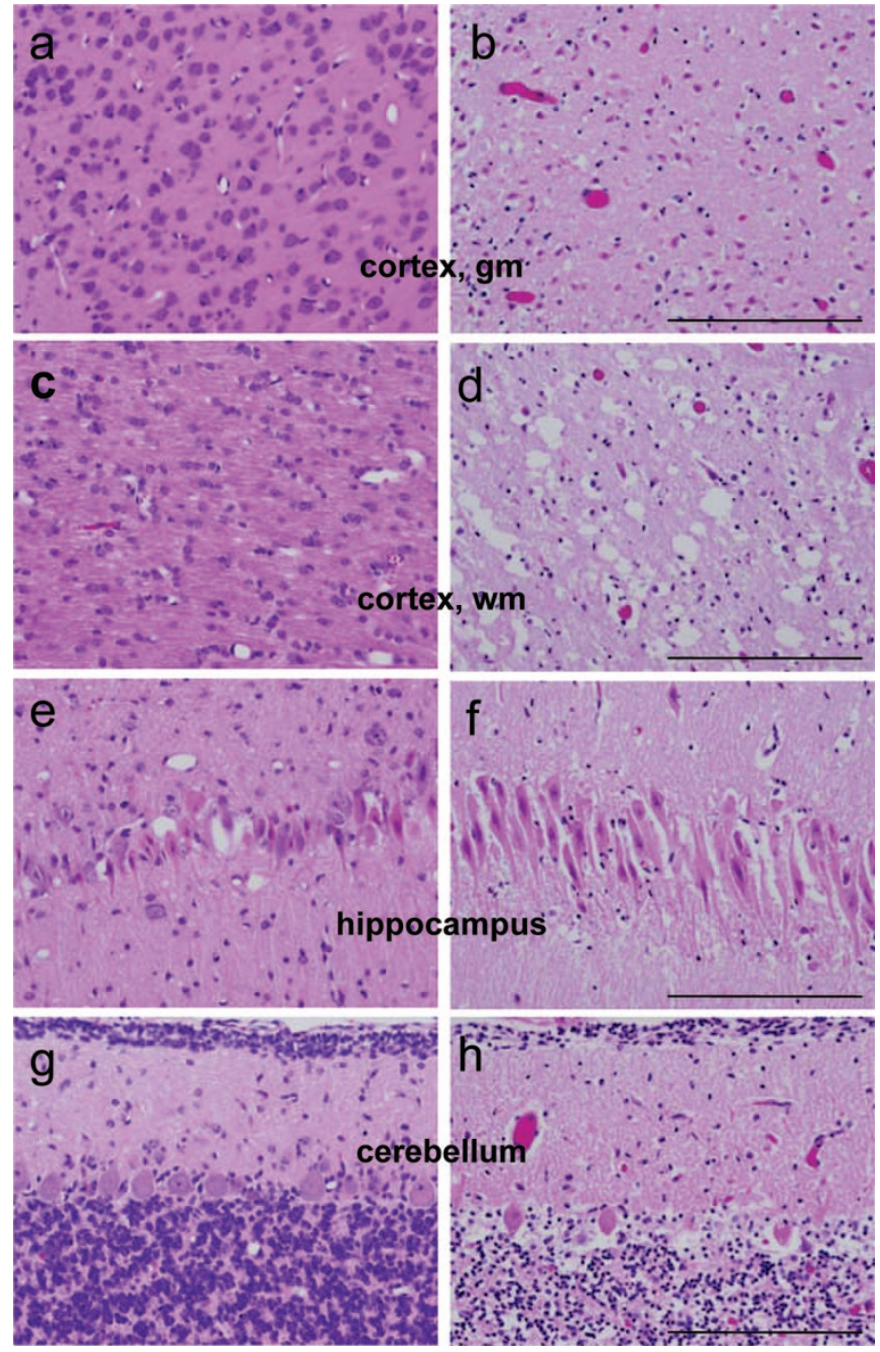

Figure 5. Hematoxylin and eosin staining in the gray matter of the cerebral cortex $(a$ and $b$ ), white matter of the cerebral cortex ( $c$ and $d$ ), hippocampus ( $e$ and $f)$, and cerebellum ( $g$ and $h)$ in a piglet from group A $(a, c, e, g)$ and a piglet from B $(b, d, f, h)$. Scale bars $=200 \mu \mathrm{m}$.

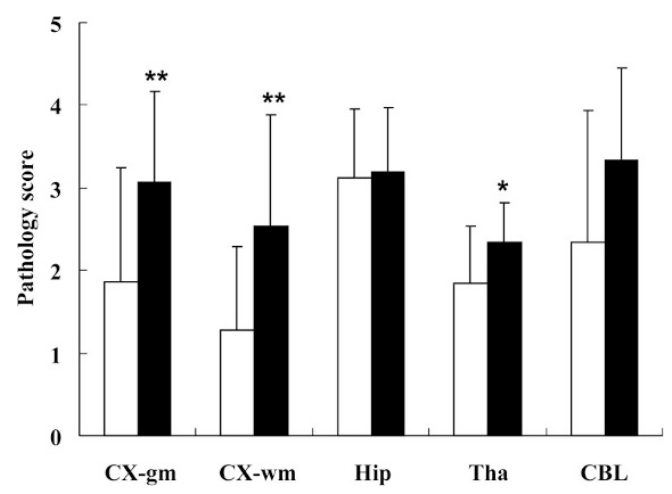

Figure 6. Mean (SD) pathology scores from five regions of the brains for each of the piglets in groups A $(n=5$; open column $)$ and B $(n=3$; black column). ${ }^{*} p<0.05,{ }^{*} p<0.01, t$ test with Bonferroni corrections. CX-gm, gray matter of the cortex; CX-wm, white matter of the cortex; Hip, hippocampus; Tha, thalamus; CBL, cerebellum.

represents a mixed vascular $\mathrm{Hb}$ oxygen saturation of capillaries, arterioles, and venules in the brain. The factors responsible for a decrease in $\mathrm{ScO}_{2}$ are the ratio of the contribution of 
arterial blood to that of capillaries and venous blood and the $\mathrm{Hb}$ oxygenation of arterial, capillary, and venous blood.

A few studies have shown a relationship between $\mathrm{ScO}_{2}$ and energy state in the brain. During hypoxia in dogs of various ages, $\mathrm{ScO}_{2}$ decreased to $7-15 \%$ of the control values and $[\mathrm{PCr}] /[\mathrm{Pi}]$ decreased to $50 \%$ of the normoxic values (11). Kurth et al. (24) studied the thresholds of $\mathrm{ScO}_{2}$ in a piglet $\mathrm{HI}$ model and found that the piglets needed hyperoxic hypercarbic ventilation to achieve over $80 \% \mathrm{ScO}_{2}$ and needed carotid artery occlusion and hypoxic gas ventilation to achieve less than $40 \% \mathrm{ScO}_{2}$. Their study indicated that the thresholds of $\mathrm{ScO}_{2}$ were $45 \%$ for an increase in lactate and $35 \%$ for a decrease in brain ATP. Ioroi et al. (25) reported that $\mathrm{ScO}_{2}$ recovered to baseline values within a few minutes of reperfusion and remained stable for $2 \mathrm{~h}$ after $\mathrm{HI}$ insults in piglets.

The reason for $\mathrm{ScO}_{2}$ values showing a negative correlation with values of $[\mathrm{PCr}] /[\mathrm{Pi}]$ are decreased cerebral oxygen consumption in advance of energy failure, which leads to an increase in venous $\mathrm{Hb}$ oxygen saturation and arterial vasodilation after HI insult. Marks et al. (26) reported delayed vasodilation and increased cerebral oxygen saturation by $12 \mathrm{~h}$ posttransient ischemia in late gestation fetal sheep. In a clinical setting, an increase in CBV was observed in asphyxiated infants within $48 \mathrm{~h}$ of birth (27) and an increase in cerebral blood flow was observed in asphyxiated infants within $24 \mathrm{~h}$ of birth (28). Furthermore, the cerebral metabolic rate of oxygen decreased $6 \mathrm{~h}$ after HI insults in newborn piglets (29), and both cerebral blood flow and cerebral metabolic rate of oxygen decreased after more severe HI insults in lambs (30-32). The results of our study agree with the results from these studies.

In the three more seriously injured piglets (group B), $\mathrm{ScO}_{2}$ values showed a positive correlation with $[\mathrm{PCr}] /[\mathrm{Pi}]$ values during the period of secondary energy failure; it is possible that these piglets developed brain edema rapidly, which induced further ischemia during secondary energy failure. In a fetal sheep HI model, the duration and pattern of cerebrovascular changes were found to be related to the severity of cerebral damage, more severe injury was associated with earlier onset of the delayed increase in $\mathrm{CBV}$ and shorter duration of CBV increase (26). The delayed increase in CBV began several hours before cortical impedance began to increase, which reflects a loss of cellular ionic homeostasis and suggests that vascular changes occur before cellular function is sufficiently deranged with regard to ion transport. Williams et al. (33) also showed that secondary intracellular edema, which was not observed after mild insults, began $7 \mathrm{~h}$ after transient severe ischemic insults in fetal sheep. A clinical study of newborn infants suffering from birth asphyxia showed decreased $\mathrm{CBV}$ and oxyHb concentration, especially in severe asphyxia, during the first $12 \mathrm{~h}$ after birth (6). In our study, a comparison of the extent of damage in different brain regions also showed that damage in the gray matter of the cortex, the white matter of the cortex, and the thalamus was significantly more severe in the animals in group B than in the animals in group A.

In fact, we previously reported that the $\mathrm{ScO}_{2}$ values of asphyxiated infants were higher or lower than those in normal- term infants within 58-72 h of birth (15). Another group has reported the usefulness of $\mathrm{ScO}_{2}$ measured by detecting transmitted light at two or more different distances from the light-emitting optodes (16). In a group of 18 severely asphyxiated term infants, those with poor outcome showed high $\mathrm{ScO}_{2}$ values between 24 and $48 \mathrm{~h}$ after birth. This result is in agreement with the concept of secondary energy failure and luxury perfusion after HI insults. In another group of 20 newborn infants surgically treated for congenital transposition of the great vessels, infants who showed below $35 \% \mathrm{ScO}_{2}$ at preoperation tended to have lower developmental scores at follow-up at 2-3 y of age (17).

However, there are some limitations to the clinical application of $\mathrm{ScO}_{2}$ measurements (34). First, the values of $\mathrm{ScO}_{2}$ cannot be compared directly to any other measurement because the $\mathrm{ScO}_{2}$ comprises a mixed value for blood in arteries, capillaries, and veins. The weighted average of arterial, capillary, and venous blood oxygenation cannot be validated easily. Second, the precision of $\mathrm{ScO}_{2}$ values may be problematic; analysis of another method for measuring $\mathrm{ScO}_{2}$ indicated that the limits of agreement after optode replacement were $-17 \%$ to $+17 \%$ (35). Therefore, further studies are required before this method can be applied to infants in a clinical situation.

In summary, we evaluated the temporal profiles of changes in $\mathrm{ScO}_{2}$ and $[\mathrm{PCr}] /[\mathrm{Pi}]$ during $\mathrm{HI}$ insult and after resuscitation. Cerebral oxygen metabolism was found to depend on changes in phosphorylation potential during secondary energy failure in asphyxiated infants.

\section{REFERENCES}

1. Younkin DP, Delivoria-Papadopoulos M, Leonard J, Subramanian VH, Eleff S, Leigh JS Jr, Chance B 1984 Unique aspects of human newborn cerebral metabolism evaluated with phosphorus nuclear magnetic resonance spectroscopy. Ann Neurol 16:581-586

2. Hope PL, Costello AM, Cady EB, Delpy DT, Tofts PS, Chu A, Hamilton PA, Reynolds EO, Wilkie DR 1984 Cerebral energy metabolism studied with phosphorus NMR spectroscopy in normal and birth-asphyxiated infants. Lancet 2:366-370

3. Brazy JE, Lewis DV, Mitnick MH, Jobsis FF 1985 Noninvasive monitoring of cerebral oxygenation in preterm infants: preliminary observations. Pediatrics 75:217-225

4. Wyatt JS, Cope M, Delpy DT, Wray S, Reynolds EO 1986 Quantification of cerebral oxygenation and haemodynamics in sick newborn infants by near infrared spectrophotometry. Lancet 2:1063-1066

5. Edwards AD, Wyatt JS, Richardson C, Delpy DT, Cope M, Reynolds EO 1988 Cotside measurement of cerebral blood flow in ill newborn infants by near infrared spectroscopy. Lancet 2:770-771

6. van Bel F, Dorrepaal CA, Benders MJ, Zeeuwe PE, van de Bor M, Berger HM 1993 Changes in cerebral hemodynamics and oxygenation in the first 24 hours after birth asphyxia. Pediatrics 92:365-372

7. Wickramasinghe YA, Livera LN, Spencer SA, Rolfe P, Thorniley MS 1992 Plethysmographic validation of near infrared spectroscopic monitoring of cerebral blood volume. Arch Dis Child 67:407-411

8. Bucher HU, Edwards AD, Lipp AE, Duc G 1993 Comparison between near infrared spectroscopy and 133Xenon clearance for estimation of cerebral blood flow in critically ill preterm infants. Pediatr Res 33:56-60

9. Kusaka T, Isobe K, Nagano K, Okubo K, Yasuda S, Kondo M, Itoh S, Onishi S 2001 Estimation of regional cerebral blood flow distribution in infants by near-infrared topography using indocyanine green. Neuroimage 13:944-952

10. Yoxall CW, Weindling AM, Dawani NH, Peart I 1995 Measurement of cerebral venous oxyhemoglobin saturation in children by near-infrared spectroscopy and partial jugular venous occlusion. Pediatr Res 38:319-323

11. Nioka S, Chance B, Smith DS, Mayevsky A, Reilly MP, Alter C, Asakura T 1990 Cerebral energy metabolism and oxygen state during hypoxia in neonate and adult dogs. Pediatr Res 28:54-62

12. Hueber DM, Franceschini MA, Ma HY, Zhang Q, Ballesteros JR, Fantini S, Wallace D, Ntziachristos V, Chance B 2001 Non-invasive and quantitative near-infrared haemoglobin spectrometry in the piglet brain during hypoxic stress using a frequency-domain multidistance instrument. Phys Med Biol 46:41-62 
13. Kusaka T, Isobe K, Nagano K, Okubo K, Yasuda S, Kondo M, Itoh S, Hirao K, Onishi S 2002 Quantification of cerebral oxygenation by full-spectrum near-infrared spectroscopy using a two-point method. Comp Biochem Physiol A Mol Integr Physiol 132:121-132

14. Ijichi S, Kusaka T, Isobe K, Islam F, Okubo K, Okada H, Namba M, Kawada K, Imai T, Itoh S 2005 Quantification of cerebral hemoglobin as a function of oxygenation using near-infrared time-resolved spectroscopy in a piglet model of hypoxia. J Biomed Opt 10:024-026

15. Kusaka T, Isobe K, Kawada K, Ohtaki Y, Itoh S, Hirao K, Onishi S 1998 Postnatal changes in the cerebral oxygenation in normal and asphyxiated neonates. Proc SPIE Int Soc Opt Eng 3194:92-102

16. Toet MC, Lemmers PM, van Schelven LJ, van Bel F 2006 Cerebral oxygenation and electrical activity after birth asphyxia: their relation to outcome. Pediatrics 117:333339

17. Toet MC, Flinterman A, Laar I, Vries JW, Bennink GB, Uiterwaal CS, Bel F 2005 Cerebral oxygen saturation and electrical brain activity before, during, and up to 36 hours after arterial switch procedure in neonates without pre-existing brain damage: its relationship to neurodevelopmental outcome. Exp Brain Res 165:343-350

18. Kusaka T, Matsuura S, Fujikawa Y, Okubo K, Kawada K, Namba M, Okada H, Imai $\mathrm{T}$, Isobe K, Itoh S 2004 Relationship between cerebral interstitial levels of amino acids and phosphorylation potential during secondary energy failure in hypoxicischemic newborn piglets. Pediatr Res 55:273-279

19. Isobe K, Kusaka T, Fujikawa Y, Kondo M, Kawada K, Yasuda S, Itoh S, Hirao K, Onishi S 2000 Changes in cerebral hemoglobin concentration and oxygen saturation immediately after birth in the human neonate using full-spectrum near infrared spectroscopy. J Biomed Opt 5:283-286

20. Kitai T, Tanaka A, Tokuka A, Tanaka K, Yamaoka Y, Ozawa K, Hirao K 1993 Quantitative detection of hemoglobin saturation in the liver with near-infrared spectroscopy. Hepatology 18:926-936

21. Lorek A, Takei Y, Cady EB, Wyatt JS, Penrice J, Edwards AD, Peebles D, Wylezinska M, Owen-Reece H, Kirkbride V, Cooper CE, Aldridge RF, Roth SC, Brown G, Delpy DT, Reynolds EO 1994 Delayed ("secondary") cerebral energy failure after acute hypoxia-ischemia in newborn piglet: continuous 48-hour studies by phosphorus magnetic resonance spectroscopy. Pediatr Res 36:699-706

22. Younkin DP, Wagerle LC, Chance B, Maria J, Delivoria-Papadopoulos M 1987 31P-NMR studies of cerebral metabolic changes during graded hypoxia in newborn lambs. J Appl Physiol 62:1569-1574
23. Thoresen M, Haaland K, Løberg EM, Whitelaw A, Apricena F, Hankø E, Steen PA 1996 A piglet survival model of posthypoxic encephalopathy. Pediatr Res 40:738748

24. Kurth CD, Levy WJ, McCann J 2002 Near-infrared spectroscopy cerebral oxygen saturation thresholds for hypoxia-ischemia in piglets. J Cereb Blood Flow Metab 22:335-341

25. Ioroi T, Peeters-Scholte C, Post I, Leusink C, Groenendaal F, van Bel F 2002 Changes in cerebral haemodynamics, regional oxygen saturation and amplitudeintegrated continuous EEG during hypoxia-ischaemia and reperfusion in newborn piglets. Exp Brain Res 144:172-177

26. Marks KA, Mallard EC, Roberts I, Williams CE, Sirimanne ES, Johnston B, Gluckman PD, Edwards AD 1996 Delayed vasodilation and altered oxygenation after cerebral ischemia in fetal sheep. Pediatr Res 39:48-54

27. Wyatt JS, Cope M, Delpy DT, Richardson CE, Edwards AD, Wray S, Reynolds EO 1990 Quantitation of cerebral blood volume in human infants by near-infrared spectroscopy. J Appl Physiol 68:1086-1091

28. Pryds O, Greisen G, Lou H, Friis-Hansen B 1990 Vasoparalysis associated with brain damage in asphyxiated term infants. J Pediatr 117:119-125

29. Tichauer KM, Brown DW, Hadway J, Lee TY, St Lawrence K 2006 Near-infrared spectroscopy measurements of cerebral blood flow and oxygen consumption following hypoxia-ischemia in newborn piglets. J Appl Physiol 100:850-857

30. Rosenberg AA 1986 Cerebral blood flow and $\mathrm{O}_{2}$ metabolism after asphyxia in neonatal lambs. Pediatr Res 20:778-782

31. Rosenberg AA, Murdaugh E 1990 The effect of blood glucose concentration on postasphyxia cerebral hemodynamics in newborn lambs. Pediatr Res 27:454-459

32. Shadid M, Moison R, Steendijk P, Hiltermann L, Berger HM, van Bel F 1998 The effect of antioxidative combination therapy on post hypoxic-ischemic perfusion, metabolism, and electrical activity of the newborn brain. Pediatr Res 44:119-124

33. Williams CE, Gunn A, Gluckman PD 1991 Time course of intracellular edema and epileptiform activity following prenatal cerebral ischemia in sheep. Stroke 22:516521

34. Greisen G 2006 Is near-infrared spectroscopy living up to its promises? Semin Fetal Neonatal Med 11:498-502

35. Dullenkopf A, Kolarova A, Schulz G, Frey B, Baenziger O, Weiss M 2005 Reproducibility of cerebral oxygenation measurement in neonates and infants in the clinical setting using the NIRO 300 oximeter. Pediatr Crit Care Med 6:344-347 